\section{Ant Address}

\section{THE RELATION OF THE MEDICAL PROFESSION TO WAR.}

Being the Inaugural Address to a Course of Lectures, on Army Medical Administration and Duties, at the West London Hospital on JANUARY 20Th, 1906.

By SURGEON-GENERAL A. H. KEOGH, C.B., DIRECTOR-GENERAL OF THE ARMY MEDICAL SERVICE.

Genthmen,-My friend Mr. Keetley, animated by a spirit of true patriotism, has represented to me that there are many members of our profession in civil life who are desirous of knowing in what way they can assist the country in time of war, without having to join one or other of the volunteer units in which opportunities, limited or otherwise, are afforded for becoming acquainted with the relation which the profession of medicine bears to the profession of arms. So convinced am I that this relationship is a very definite one, and that the potential energy of the medical profession is a factor capable of contributing to or hindering the successful issue of campaigns, and that the dissemination of knowledge as to the rôle of a medical service in an army is a first step in its efficiency, that it is impossible for me to neglect for a moment the suggestion of Mr. Keetley. The usefuluess of a member of the medical profession in an army depends largely upon his appreciation of the fact that he is a member of an organization designed for special and liverse purposes. To have been trained in medicine is essential before a man can play any part in the rôle of this organization; and while the different duties assigned to the various parts of the organization require differentiation of function to produce a high degree of efficiency in the whole, a common knowledge of definite facts is required in every individual member of the system. To-afford information on specific points I have found it necessary, of course, to procure for you experts in special branches of medical work in the army ; but before you can be in a position to fully appreciate the interdependence of the varieties of special work and special knowledge, a general knowledge of the army and of its component parts as well as a general knowledge of the medical service and its component parts are essential. The series of discourses which will be presently begun will accordingly be dealt with on these lines.

Having been invited to open these lectures, I have chosen as my subject the relation of the medical profession to war. I am encouraged to embark upon this topic because I find so many distinguished members of the profession who seek information upon the matter. But I cannot, in the limited time afforded me, do more than touch the fringe of the subject; for the story of the evolution of the medical service of the British army is the story of the evolution of modern methods of warfare, and it is almost impossible to adequately deal with the matter without discoursing on the historical events which have led up to the modern Royal Army Medical Corps. This it is impossible for me to do. But those of you who care to seek information on matters historical will find much useful information in a series of articles by Captain Howell now appearing in the Royal Army Medical Corps Journal. Let it suffice to say that there has been a gradual progress from a state of affairs infinitely crude to one in which, complicated though its mechanism may be, you have a co-ordinated machinery, well constructed and well adapted for the purpose which it is designed to serve. Time was when an army in the field was adequately served by a staff of physicians and surgeons engaged, one might say, for the occasion, when no serious attempt was made to solve the problems now presented to medical men, and where, moreover, the resources of medical science were so limited that medicine could find no place in the administrative system. But those days have passed, and the evolution of the merlical service has proceeded, till to-day we tind it a special branch of the medical profession and of the army, requiring in its members a training for the acquirement of a special knowledge essential for efficiency. The altered conditions of modern warfare, the constantly accumulating experience of our officers in our numerous wars, the enormous improvement in medical education, and the general advance in professional knowlege, have been the circumstances which have determined the line along which the evolution of the medical branch of the army has proceeded. To-day, gentlemen, although I am far from saying that our service is in as perfect a state as the British medical profession could make it, $I$ have no hesitation in saying that in its general plan of organization, in the enthusiasm which animates its members, officers, nurses, non-commissioned officers and men, and in its traditions, it is better adapted for its purpose than that of any other European army. A great principle which it has been necessary to assert and to carry into practice is differentiation of duties in accordance with the tastes and aptitude of individuals. The army medical officer was formerly supposed to be an Admirable Crichton-a first-class physician, a first-class surgeon, an expert sanitarian, a capable administrator, good at ophthalmology, otology, gynaecology, and all other special subjects, as well as an expert in adapting his work to the science and art of war, with which, also, he was required to be acquainted. These various attainments cover a wider field of knowledge than that expected from even the general practitioner in civil life.

The existence of this specialization, like all specialities, constitutes a danger, against which we must continue to guard ourselves. In the service of the country it is essential that the profession as a whole should work for the common good, and that there should not be two medical professions, but one. While, therefore, we in the army make every effort to close up the interval which specialization may cause between the civil and military branches of the medical profession, so also have you resolved to approach near to us by becoming acquainted with the organization which represents the contribution of the profession towards national defence.

Recent advances in army medical organization have provided for the maintenance of touch with the civil profession. The establishment of an Army Medical College in your midst, the throwing into your great schools of officers of the medical corps, taking note of your work and rbreathing the atmosphere of progress, is our method of maintaining touch.

The arrangements made for this purpose have been of a very comprehensive nature. We are establishing in London an Army Medical College, and laboratories and hospital replete with all modern improvements. In addition, 'we propose to continue to avail ourselves of the unrivalled facilities which the civil hospitals in London afford, and we have been met more than half way by the authorities. Even on a necessarily imperfect. system, we have already given to our officers who have been abroad six months' further study in the London medical schools, and have paid their fees for them, and in the short time which has elapsed since we began no fewer than 140 captains who have been serving in various parts of the world have been able to avail themselves of this opportunity. In addition, we have allowed 20 probationers to return to their hospitals for one year to hold various medical and surgical resident appointments. We have sent two to the Continent of Europe to study. We have succeeded in appointing one for a prolonged period to the Lister Institute for special work. Gentlemen, if I had not another word to say, I think this record is sufficient to establish my claim that recent army medical administration is alive to modern educational necessities, and to the necessity for keeping in touch with the civil profession.

I cannot put into words our other exertions on behalf of medical officers who have sought opportunities to improve their professional knowledge and obtain special qualifications. Suffice it to say that during the short period which I am reviewing, our officers have been enabled to take degrees in the Universities of London, Cambridge, Durham, and elsewhere, and numerous officers have taken diplomas in sanitary science. I can confidently assert that there is no other public medical service which has done so much in the interests of professional efficiency in this direction as has the Royal Army Medical Corps. Your method of maintaining touch with us is attained by the great Volunteer medical corps of London, Glasgow, 
Manchester, and elsewhere, and, we may now say, by the series of lectures which I at your wish inaugurate to-day.

There is considerable misapprehension as to the lines upon which the medical corps of the army has been seeking efficiency. I fear that the civil mind is satisfied with the assurance that provision is being made for recognition of professional merit, for advanced education, and for research. But a medical corps administered only with a regard to these most important matters is imperfectly equipped in relation to its prime raison detre-war. The best type of military mind is only satisfied with a corps which is designed with a view to the fulfilment of functions which are auxiliary to the fighting and winning of battles.

To eomply with the conditions of modem warfare an efficient medical corps must satisfy certain requirements. It must possess some knowledge of the art of war and of military history to enable it to co-ordinate itself to the military requirements of the moment, and to protit by past experience. It must be so organized that it is capable of receiving, housing, feeding, and transporting troops non-effective from disease or injury. It must be capable of providing medical and surgical aid as nearly as possible equal to that which is at the disposal of those who remain at home. It must especially be brought to the highest possible pitch of perfection to enable it to prevent disease in the fighting force. An efficient medical corps is in theory and in actual practice a potent factor in the fighting and winning of battles. The medical corps is maintained for war, and it is as to its readiness and capacity for adapting itself to war conditions that the medical profession must be judged.

A perfect medical corps is one which, without excessive impediment, removes troops non-effective from disease or injury, disposes of its hospitals in positions least likely to embarrass military movements or supplies, quickly restores to the ranks those cured of disease or injury, but above all things prevents the occurrence of disease, and thus maintains the fighting powers of an army.

Any allusion to army medical administration would be incomplete without very definite reference to sanitation and the investigation and prevention of disease.

There never was a body of men more competent to apply sanitary principles to the prevention of disease in war, to supply from among its members men selected to investigate the problems which the diseases of armies present for solution, than those who are receiving their medical education in the universities and schools of the present day; and there can be no doubt whatever that if army medical administration is alive to the opportunities which the profession affords it, the sanitary work of the corps in the future will have a useful career in the military service.

We have made a beginning in the establishment of an Army Sanitary Branch. Officers specially qualified in State Medicine and endowed with the qualities which go to make sanitarians have been appointed so that each district has its sanitary expert during peace, and sanitary experts are therefore available for war. These officers are being rapidly provided with sanitary laboratories, and are given a free hand, unhampered by special regulations. Non-commissioned officers and men are being trained in London to act as laboratory attendants. The movement is in its early stage at present, but so far there has been no hitch. Every layman nowadays knows that preventive medicine ought to be able to contribute to maintain the fighting strength of an army in the field. I hold strongly that much of the wastage of armies is preventable, and that a portion of our war establishment now allotted for curative purposes can be with advantage allotted to prevention. The sanitary work of the medical corps has begun and must go forward. The main object of its formation and of its existence is to devise methods for the prevention of disease in the field. This includes scientific research. The material for research is abundant. The position of the army medical officer in relation to scientific medicine is unique. It is the duty of the administrators to assist him to avail himself of the opportunities at his disposal. This is being done. Under the auspices of the Royal Society at the present moment two series of researches are being conducted by army medical officers. In addition to the sanitary laboratories which I have already mentioned, clinical laboratories are being set up in our hospitals, and their influence upon research must be enormous.

I might continue to place before you and to comment upon various items in the different departments of our work in which the medical service of the army can contribute to army efficiency.

If you will turn your attention in detail to any one of these departments, you will readily appreciate what is involved in the way of study and work. Let me take for illustration an instance which will readily come home to you: Imagine yourself directed to establish and work a hospital in war. You have but begun when you have provided a professional staff; you have to accumulate tents and stores; you have to arrange for food and bedding to an extent and of a quality suitable to the special circumstances; you have to receive, to treat, feed, and clothe soldiers sick and wounded, maintain communication with their corps, remove them from your area either back to their corps, clothed and equipped, or by convoy to the base of operations, where other medical functionaries have their allotted problems. How are these things done? That is what you have to learn. Your professional knowledge affords you no aid. Or, to take an unfamiliar example, imagine the battle of the Yalu. Regard yourself as responsible for the application of the principles I have mentioned, before, during, and after an engagement of this description, and a little consideration will suffice to convince you that only an intimate acquaintance with the detailed management and organization of all units, military and medical, will enable you to stccessfully assist the operations of war. These things you desire to learn, these things you must learn if you are ready and willing to assist the country in the future. I think that you should first learn the organization of the medical services for war, if you would understand the system which you will find exists in time of peace; for many of the essential differences between civil and military medical organization are explained by the conditions incidental to active service in the field.

But the Army Medical Service is further responsible for its own internal economy. Too often does the civil mind dwell only upon the technical requirements of sick and wounded, without recollecting that the duties to be performed in relation to the fighting forces can only be adequately provided for by an efficient, disciplined, and educated personnel. In other words, the administration of the personnel of the Medical Corps in peace is a necessary factor for its successful work in war. You will, I hope, have opportunities of observing the scope of the work involved, and be able to estimate how we have provided for the securing of efficiency. All these things are taking place in the largest military centres, and, if naturally unknown to the layman, should no longer be unknown to the members of the medical profession who find themselves capable of assisting their brethren in the army even in the smallest degree.

I have said encugh, I think, to show you that the Army Medical Service is involved in work sufficiently varied to suit the capacity of the various individuals composing it and affording opportunities for differentiation of work. The efficiency of a medical unit depends upon the efficiency of its several parts; upon its physicians and its surgeons, and its administrators, upon its higher and lower personnel equally, upon its equipment, its discipline, its mobility, and upon its readiness to seize its opportunities, and extend its efforts under the pressure of circumstances incidental to war-the rôle of the individual member demands the possession of all the military and medical virtues.

During the late South African war, when medical men for the moment began to think of military medical affairs, one not infrequently heard of schemes by which civil effort would provide for the supply of personnel, and of even complete hospitals in war, such hospitals to be affiliated to, or exist as, offshoots from the great civil institutions. The idea was undoubtedly a good one, but as the years have passed the zeal and enthusiasm has lessened. It probably remains for the Red Cross Society to inaugurate system which will deal with this great problem of expansion-and when the country emulates the example of Japan in dealing seriously with this branch of work, the education of the profession in hospital administration will have to be undertaken.

Perhaps I have said enough to indicate to you the lines 
upon which the series of lectures should be framed. You will probably deem it right that the subject should be dealt: with upon elementary lines; indeed, you may regard this: as necessary. I take leave to think that most of you possess no acquaintance with military affairs; that the constitution of, say, an army corps is unknown to you; that its allotment of divisions and brigades are mere names to you; that the proceedings adopted to call into existence the machinery for mobilizing a force for the fieldi. and especially what part the medical branch plays in these things and these proceedings are also matters with which you cannot be expected to be familiar.

Perhaps you will allow me to recapitulate the present position of the medical corps in relation to the problem of efficiency, and to emunciate the principles upon which we have, as the phrase goes, reorganized the medical service. In the front rank we place professional efficiency, and the means of attaining it. We desire to adapt to our purposes the resources of modern science; and for this reason we desire a close connexion with the profession, and we have, as I think, successfully endeavoured to raise the standard of work in our large institutions. We have borne in mind that to raise the standard of work we have to provide for the training of the subordinate personnel more than for that of the medical officers. I think I can say that we have encouraged medical officers and matrons to improve the method of training of our men, and that we endeavour to allocate to all ranks the class of work which the individuals prefer or for which they are best suited. In this direction we claim to have grasped the most important factor determining efficiency: The army medical officer, like every member of the profession, has his special preferences.

In the series of lectures which are to follow you will become acquainted with the details of medical organization in peace and war. Should the occasion ever arise when it may be possible for you, busy men as you are, to take a part in the great work, $I$ cannot doubt that you will be the more useful to the army because of a little preliminary education.

\section{Climital hemarks}

ON A

\section{Case OF TUBerculous Disease. OF' THE LUNGS AND LARYNX,}

SHOWING THE NEED FOR THE OOMPULSORY NOTIFICATION OF PHTHISIS.

BY. BYROM BRAM WELL, M.D., F.R.C.P.FD, PHYSICIAN TO THE ROYAL INFIRMARY, EDINBURGH.

Gentlemen,-This girl, aged: 21 , is a kitchenmaid. She is suffering from tuberculous disease of the lungs and larynx. She was in the hospital in March last, and was treated for some time by the open-air treatment (on the balcony). The sputum was teeming with tubercle bacilli I have never seen any case in which. they were more numerous; great clumps of bacilli, in addition to innumerable isolated bacilli, were scattered abundantly throughout the sputum.

When the patient discharged herself she told me that it was her intention to take a situation as a kitchenmaid in a public institution. I told her that she must not think of doing this. I seriously warned her that it would be very wrong to do so-that: it would be dangerous to other people.

Well, we lost sight of her for some months. She applied for readmission a few days ago. Her condition is very much the same as it was in March; the lungs and larynx are extensively diseased; the sputum still contains large numbers of tubercle bacilli, though not the great clumps which were present when she was in the hospital before ; the large clumps of tubercle bacilli were probably due to the breaking down and evacuation of tuberculous deposits in the larynx. The patient tells me that, notwithstanding my advice, immediately after her discharge in March she applied for and obtained a situation as kitchenmaid in an eating house. She says that the staff consisted of six in the kitchen and nineteen in the shop it was, therefore, a very large establishment. The cus- tomers must have been very numerous to keep such a large staff employed.

Observe the danger of such a state of matters-a girl whose sputum was literally teeming. with. tubercle bacilli; employed as kitchenmaid in a public eatinghouse which supplied food to a very large number of customers daily!

A case like this shows the necessity of the public supervision of cases of phthisis. Some seven years ago I published a long and elaborate article on the compulsory notification of phthisis, ${ }^{2}$ and I think conclusively showed the advisability, nay, the necessity, of such a measure, if a real and serious attempt is to be made to eradicate this terrible disease.

In that article and in a series of lectures which were subsequently published in the Lancet, I exhaustively considered the arguments in favour of and against a system of compulsory notification specially adapted for phthisis. It is obvious that unless you know where the cases of phthisis are located you cannot take the proper and necessary measures to limit the spread of the infection. At that time (1899) the profession in this country would not listen to the proposal; it is not, I think, an exaggeration to say that it was received with a very cold shoulder by almost everyone. People could not be made to see that compulsory notification, as applied to phthisis, carries with it quite different results, in the way of preventive measures, from the preventive measures (isolation, removal to a hospital, etc.) which are required in the case of the ordinary contagious and infectious diseases (scarlet fever, small-pox, typhus, etc.).

Further consideration of the subject has made me more convinced than ever that compulsory notitication is essential, if a real and serious effort is to be made to eradicate the disease. This opinion is now strongly held by Koch and many other leading authorities. There are I think, indications that this opinion is' gradually gaining ground in this country; but we are still very much behindhand, far too conservative in this matter. The Americans take a very much more enlightened. view of this question than we do; the compulsory notification. of phthisis has been widely adopted in the United States of America. In a recent letter, $\mathrm{Mr}$. William $\mathrm{H}$. Baldwin of Washington tells me that already in more than half of the cities in the United States with a population of over $48,0.00$, such a law has been passed, and is more or less thoroughly enforced. He also states that in the great majority of cases the reports are kept private, and that there is no difficulty in keeping them private. Now if the compulsory notification of phthisis has been adopted and works well in America, there is no reason why it should not be adopted and why it should not work well here.

The case which I have brought before your notice this morning shows in a very forcible way the necessity for such a measure. If this case had. been. under proper medical supervision, this patient would never have been allowed to act as a kitchenmaid in a public eating-house. Further, means would have been taken to see that she disinfected her sputum. The prevention of phthisis is a very simple matter in comparison with the prevention of many of the contagious and infectious diseases. In phthisis, isolation and removal to hospital are not called for except in a comparatively small number of what I term dangerous cases. Most patients affected. with phthisis may be allowed to mix with their fellows and to follow their ordinary occupations. What is required is the destruction or thorough disinfection of the sputum. Now, unless you know where the cases of phthisis are located, you cannot see that they are properly instructed in respect to the measures which slould be adopted for the destruction or disinfection of the sputum, and you cannot see (even if they have the knowledge) that they are habitually practising the comparatively easy and simple measures which are necessary: for destroying the poison and preventing its dissemination; in other words, for preventing the spread of the disease to other people. It would be hazardous to speculate as to the number of people to whom this patient may have been the means of communicating the disease in other words, how many cases of phthisis might have been prevented if, by means of a proper system of compulsory notiffeation' and supervision, this patient lyad been rendered innocuous as a disseminator of the poison (the tubercle bacilli). I do not of course mean to suggest that 